\title{
Non-existence of Duopoly Equilibria: A Simple Numerical Example
}

\author{
Jean-Marc Bonnisseau and Michael Florig \\ Received April 28, 2004; revised version received February 9, 2005 \\ Published online: May 9, 2005 \\ (C) Springer-Verlag 2005
}

We give a simple example to the non-existence of duopoly equilibrium in pure strategies in an economy with two goods and two types of consumers. This extends also the discussion on the incentive for trade in an oligopolistic framework initiated in Cordella and Gabszewicz (1998).

Keywords: imperfect competition, duopoly equilibrium.

JEL Classification: D50, D43.

\section{Introduction}

The purpose of this paper is twofold. First, we propose a very simple numerical example of a duopoly with two consumers having extremely simple preferences, i.e., linear preferences. According to the definition of a Cournot-Walras equilibrium (Gabszewicz and Vial, 1972), firms choose production levels and then a Walras equilibrium is played in the resulting exchange economy. In our example, each firm has only one shareholder, so firms objectives are unambiguously defined as utility maximization of its shareholder's utility (e.g., Dierker and Grodal, 1999; Dierker, Dierker and Grodal, 2001), which does not depend on the price normalization (see Gabszewicz and Vial, 1977, for the problem when the objective of the firm is the profit). For each strategy, utility levels are unique at the Walras equilibrium of the corresponding exchange economy. Therefore, we do not have to choose an arbitrary selection (e.g., Dierker and Grodal, 1986). 
Best reply correspondences are computed, and, we deduce that no duopoly equilibrium in pure strategies exists. Nevertheless, an equilibrium in mixed strategies exists since the sufficient assumptions for the existence are satisfied (compactness of the strategy sets and continuity of the payoffs).

Roberts and Sonnenschein (1997) proved that a Cournot-Walras equilibrium in pure strategies does not always exist. Dierker and Grodal (1986) proved that even mixed strategy Cournot-Walras equilibrium may fail to exist if a particular price selection is chosen. Nevertheless, these authors propose examples without completely specifying them. They prove the existence of a specification which leads to non-existence of an equilibrium by applying the Debreu-Mantel-Sonnenschein Theorem. As far as we know, no numerical completely specified counter-example for the existence of an oligopoly equilibrium in pure or mixed strategies has been proposed in the literature. The prevailing point of view seems to be that it would be very hard to find the algebraic specification of the preferences of such a counter-example (e.g., Roberts and Sonnenschein, 1972).

The non-existence of equilibrium is due to the lack of continuity of the best response of one duopolist. Note that the two duopolists are not symmetric, which allows to remove some exceptional symmetric equilibria, which exist even with discontinuous best-reply functions. By exceptional, we want to say that they exist only for a small set of parameters. We also remark that autarky is not an equilibrium. This is in contrast with the case of an exchange economy, where autarky is always an oligopoly equilibrium (see, Gabszewicz and Michel, 1997). With production possibilities, it appears in our example that, at the autarkic allocation, one duopolist puts all its initial endowment in the production process even if the productivity is low. If the possibility of exchange is open, then he prefers to produce nothing and to exchange his initial endowment against the initial endowment of the other duopolist. So, autarky is not robust to unilateral deviation.

The second point of our example is that it allows us to go further in the discussion initiated in Cordella and Gabszewicz (1998). They consider a Ricardian economy which is almost the same as the one presented below apart from the preferences of the consumers. The analysis of Cordella and Gabszewicz is that, even if the incentives for trade are maximal, the noncooperative strategic behavior of economic agents leads to the autarkic outcome without any trade. The paradox with our example is that we reduce the incentives for trade since the consumer of one type is not 
only interested in the commodity for which the consumer of the other type has a comparative advantage. Thus, we may expect that the autarkic oligopoly equilibrium will remain an equilibrium. But this does not hold true and even more, there is no pure strategy equilibrium at all. In Cordella and Gabszewicz, the strategic behavior of the two duopolists destroys the incentive for trade and autarky is the only solution. One easily checks that, in their example, no nontrivial mixed strategy equilibrium exists. So the probability of trade at equilibrium is zero. In our example, since autarky is not an equilibrium, trade takes place with a positive probability. Therefore in a strategic setting lower incentives for trade may result in a higher probability that trade takes place.

\section{Example}

We consider an economy with two commodities $L=\{A, B\}$, two types of consumers $I=\{1,2\}$ each one entirely owning one firm labelled by the type of its owner. The consumption set of each consumer is $R_{+}^{2}$ and the utility function $u_{i}: R_{+}^{2} \rightarrow R$ is defined by $u_{i}\left(x_{i}\right)=b_{i} \cdot x_{i}$ with $b_{1}=(1,1)$ and $b_{2}=(3,1)$. The first type of consumers have a global initial endowment equal to $\omega_{1}=(2,0)$ and the second one $\omega_{2}=(0,2)$. The firms' production sets are

$$
\begin{aligned}
& Y_{1}=\left\{y \in R^{2} \mid y_{A} \leq 0, y_{B}=-\frac{1}{2} y_{A}\right\} \quad \text { and } \\
& Y_{2}=\left\{y \in R^{2} \mid y_{B} \leq 0, y_{A}=-\frac{1}{2} y_{B}\right\} .
\end{aligned}
$$

Allowing for free-disposal would not alter our result. One may think of each type being a non-atomic set of identical consumers. Consumers are thus supposed to act competitively. They obtain their revenue from their share in the firms and the value of their initial endowments.

The set of strategies of a firm is the set of productions, which are feasible with the initial endowments of the shareholders. So, $S_{1}=$ $\left\{y^{2} \mid-2 \leq y_{A} \leq 0,2 y_{B}=-y_{A}\right\} \quad$ and $\quad S_{2}=\left\{y \in R^{2} \mid-2 \leq y_{B} \leq 0\right.$, $\left.2 y_{A}=-y_{B}\right\}$.

If firms choose strategies $y=\left(y_{1}, y_{2}\right) \in S_{1} \times S_{2}$, then given $p \in R_{++}^{2}$ each consumer of type $i$ demands an element of $d_{i}\left(p, p \cdot\left(y_{i}+\omega_{i}\right)\right)$ which is the solution of the utility maximization problem: 


$$
\left\{\begin{array}{l}
\operatorname{maximize} b_{i} \cdot x \\
p \cdot x \leq p \cdot\left(y_{i}+\omega_{i}\right) . \\
x \geq 0
\end{array}\right.
$$

The final allocation of the consumers are equilibrium allocations of the exchange economy $\left(b_{i}, y_{i}+\omega_{i}\right)$. By Gale $(1957 ; 1976)$, for each $y \in S_{1} \times S_{2}$ utility levels of the consumers $v_{i}(y)$ are uniquely determined, i.e., the utility levels of the consumers depend only on the level of production of the firms, not on the particular Walras equilibrium of the exchange economy associated to the production levels.

The firms objective will be to maximize their owners' utility which is unambiguously defined here (e.g., Cordella and Gabszewicz, 1997). For this reason the price normalization problem as in Gabszewicz and Vial (1997) does not apply here. In the present set up, utility maximization of the consumers utility coincides with real wealth maximization (Dierker and Grodal, 1999) and S-efficiency (Dierker, Dierker and Grodal, 2001). So the present example gives a counter-example to the existence of a pure strategy equilibrium with these objectives of the firms.

Definition 2.1: A duopoly equilibrium is a pair of strategies $y \in S_{1} \times S_{2}$ such that for all $i \in I$ and for all $z \in S_{i}, v_{i}(y) \geq v_{i}\left(z, y_{i^{\prime}}\right)$ with $i^{\prime} \neq i$.

To simplify the exposition, we consider that the strategy set of the first duopolist is $[0,2]$ (resp. $[0,1]$ for the second duopolist), and, if he chooses $a^{1} \in[0,2]$ (resp. $\left.a^{2} \in[0,1]\right)$ the production is $\left(a^{1}-2,1-\left(a^{1} / 2\right)\right)$ (resp. $\left(a^{2},-2 a^{2}\right)$ ), and the initial endowments are $\left(a^{1}, 1-\left(a^{1} / 2\right)\right)$ (resp. $\left.\left(a^{2}, 2-2 a^{2}\right)\right)$ in the associated exchange economy. The price normalization of prices is defined by $p_{B}=1$.

In an exchange economy with the two consumers, if the total initial endowments are $e$ and the initial endowments of the first consumer is $e^{1}$, then the equilibrium price $p_{A}$ is:

$$
\left\{\begin{array}{ll}
{[1,3]} & \text { if } e_{A}^{1}=0 \text { and } e_{B}^{1}=e_{B}>0 \\
1 & \text { if } e_{A}^{1}+e_{B}^{1} \geq e_{B} \text { and } e_{A}^{1}>0 \\
\frac{e_{B}-e_{B}^{1}}{e_{A}^{1}} & \text { if } e_{A}^{1}+e_{B}^{1}<e_{B}<3 e_{A}^{1}+e_{B}^{1} \text { and } e_{A}^{1}>0 \\
3 & \text { if } 3 e_{A}^{1}+e_{B}^{1} \leq e_{B} \text { and } e_{B}^{1}<e_{B}
\end{array} .\right.
$$

We remark that the trades of the consumers are always in the same direction, that is, the first consumer sells good A and buys good B and the 
converse for the second consumer. Furthermore, the participation to the market is profitable for the first consumer only if the price is strictly greater than 1, and, for the first consumer if the price is strictly lower than 3. The interest of the first consumer is to get the highest possible price and the converse for the second consumer.

Then, a simple computation shows that for a pair of strategies $\left(a^{1}, a^{2}\right) \in[0,2] \times[0,1]$ the equilibrium price for the commodity $A, p_{A}$, is defined by:

$$
p_{A}\left(a^{1}, a^{2}\right)=\left\{\begin{array}{ll}
{[1,3]} & \text { if } a^{1}=0 \text { and } a^{2}=1 \\
1 & \text { if } 2\left(1-a^{2}\right) \leq a^{1} \text { and } a^{1}>0 \\
\frac{2\left(1-a^{2}\right)}{a^{1}} & \text { if } 0<a^{1}<2\left(1-a^{2}\right)<3 a^{1} \\
3 & \text { if } 3 a^{1} \leq 2\left(1-a^{2}\right) \text { and } a^{2}<1
\end{array} .\right.
$$

From this we deduce the objective functions of the firms which are simply the indirect utility functions $v_{i}:[0,2] \times[0,1] \rightarrow R, i=1,2$ of their respective shareholders:

$$
\begin{aligned}
& \left(v_{1}\left(a^{1}, a^{2}\right), v_{2}\left(a^{1}, a^{2}\right)\right) \\
& \quad= \begin{cases}\left(1+\frac{a^{1}}{2}, 6-3 a^{2}\right) & \text { if } 2\left(1-a^{2}\right) \leq a^{1} \\
\left(3-2 a^{2}-\frac{1}{2} a^{1}, 3\left(a^{1}+a^{2}\right)\right) & \text { if } a^{1} \leq 2\left(1-a^{2}\right) \leq 3 a^{1} . \\
\left(1+\frac{5}{2} a^{1}, 2+a^{2}\right) & \text { if } 3 a^{1} \leq 2\left(1-a^{2}\right)\end{cases}
\end{aligned}
$$

One may establish the correspondences of best response:

$R_{1}:[0,2] \times[0,1] \rightarrow[0,2]$ and $R_{2}:[0,2] \times[0,1] \rightarrow[0,1]$

$$
\begin{aligned}
& R_{1}\left(a^{2}\right)= \begin{cases}\frac{2}{3}\left(1-a^{2}\right) & \text { if } 0 \leq 5 a^{2}<2 \\
\left\{2, \frac{2}{5}\right\} & \text { if } 2=5 a^{2} \\
2 & \text { if } 2<5 a^{2} \leq 5\end{cases} \\
& R_{2}\left(a^{1}\right)=1-\frac{1}{2} a^{1} .
\end{aligned}
$$

It is now easy to show that a duopoly equilibrium does not exist. Indeed, it suffices to compute the correspondence $\rho=R_{1} \circ R_{2}$ from $[0,2]$ to itself,

$$
\rho\left(a^{1}\right)= \begin{cases}2 & \text { if } 0 \leq a^{1}<\frac{6}{5} \\ \left\{2, \frac{2}{5}\right\} & \text { if } a^{1}=\frac{6}{5} \\ \frac{1}{3} a^{1} & \text { if } \frac{6}{5}<a^{1} \leq 2\end{cases}
$$


to remark that an equilibrium strategy for the first consumer is a fixed point of $\rho$, and, to check that $\rho$ has no fixed point.

Note that the unique competitive equilibrium of the economy is $p^{*}=(1,1), x^{1 *}=(0,2), x^{2 *}=(2,0)$ and $y^{1 *}=y^{2 *}=(0,0)$ : so, no production at equilibrium but only an exchange of the initial endowments. Thus, the production possibilities are not used at equilibrium, which is not surprising since the productivities are low.

We can remark a dissimilarity in the duopolists' behaviors. Indeed, the second one can always choose a strategy, which leads to a price equal to 1 , and, then to a profitable exchange on the market. Note that, to obtain this situation, he must produce a positive quantity of good A with the low productivity $\frac{1}{2}$. On the other hand, the first duopolist can always find a strategy, which leads to a price equal to 3 , but it is profitable only if the strategy of the second consumer is less than $\frac{2}{5}$. In this case, in order to influence prices by enough, the duopolist must consume at least $\frac{8}{5}$ of the first commodity in the production process. If the strategy of the second duopolist is greater than $\frac{2}{5}$, the optimal strategy is to keep the initial endowment in the first commodity without producing the second commodity. Thus, the optimal strategy exhibits a discontinuity.

The absence of equilibria is a direct consequence of this discontinuity : the first duopolist has two types of strategies: either the highest strategy 2 or a relatively small strategy below $\frac{2}{5}$. In the first case, the best response of the second one is to choose the smallest strategy 0 , and, in the second case, to choose a relatively high strategy above $\frac{2}{3}$. In both cases, the best response of the first duopolist is to switch to the other strategy type.

\section{Acknowledgements}

We would like to thank Jean Gabszewicz, who has suggested this work, for his comments on a first version.

\section{References}

Cordella, T., Gabszewicz, J. J. (1997): “Comparative Advantage under Oligopoly." Journal of International Economics 43: 333-346.

Cordella, T., Gabszewicz, J. J. (1998): "Nice Trivial Equilibria in Strategic Market Games." Games and Economic Behavior 22, 162-169.

Dierker, H., Grodal, B. (1986): "Non-existence of Cournot-Walras Equilibrium in a General Equilibrium Model with Two Oligopolists." In: Contributions to Mathematical Economics, edited by W. Hildenbrand and A. Mas-Colell. North Holland, pp. 167-185. 
Dierker, E., Grodal, B. (1999): “The Price Normalization Problem in Imperfect Competition and the Objective of the Firm." Economic Theory 14: 257-284.

Dierker, E., Dierker, H., Grodal, B. (2001): "Objectives of an Imperfectly Competitive Firm: A Surplus Approach." In Economic Essays, edited by G. Debreu, W. Neuefeind, and W. Trockel. Berlin: Springer.

Gabszewicz, J. J., Michel, P. (1997): “Oligopoly Equilibria in Exchange Economie." In Trade, Technology and Economics. Essays in Honor of Richard G. Lipsey, edited by B. Curtis Eaton and Richard G. Harris. Cheltenham: Edward Elgar, pp. 217-224.

Gabszewicz, J. J., Vial, J. P. (1972): “Oligopoly 'à la Cournot' in a General Equilibrium Analysis.” Journal of Economic Theory 4: 381-400.

Gale, D. (1957): "Price Equilibrium for Linear Models of Exchange." Technical Report P-1156. The Rand Corporation.

Gale, D. (1976): "The Linear Exchange Model." Journal of Mathematical Economics 3: 205-209.

Roberts, J., Sonnenschein, H. (1977): “On the Foundations of the Theory of Monopolistic Competition.” Econometrica 45: 101-113.

Address of authors: - J.-M. Bonnisseau and M. Florig, CERMSEM, Université Paris 1 Panthéon-Sorbonne, 106-112 Boulevard de l'Hôpital, 75647, Paris Cedex 13, France (e-mail: jean-marc.bonnisseau@univ-paris1.fr; florig@univ-paris1.fr) 